\title{
THE EFFECT OF THE LONGSHORE DIMENSION ON DUNE EROSION
}

\author{
Jaap van Thiel de Vries ${ }^{1,2}$ Ap van Dongeren² Robert McCall $^{2}$ Ad Reniers ${ }^{3}$
}

\begin{abstract}
The effect of the longshore dimension on dune erosion is examined numerically with a 2DH process-based model XBeach. Exploratory simulations are presented to examine longshore effects due to directionally spread waves, longshore variation in topography and longshore variation in bathymetry. The simulations reveal that alongshore sediment exchange during a storm surge affects the cross-shore development of the foreshore and can locally increase or decrease storm impact on dunes substantially. This finding illustrates that dune erosion on natural coasts (which are never cylindrical or subject to longcrested waves) is an inherent 2D process for which 1D cross-shore models do not suffice without further assumptions.
\end{abstract}

Keywords: dune erosion, surfbeat, longshore sediment transport

\section{INTRODUCTION}

Large parts of The Netherlands are situated below mean sea level and are densely populated. Inundation of the hinterland is prevented with a narrow system of sea defenses that mainly consist of sandy beaches and dunes. The strength of these dunes against normative storm surge conditions is assessed every six years with an empirical dune erosion model DUROS that was developed from (large scale) flume experiments (Vellinga, 1986; Van Gent et al., 2008). Though the model is validated against many experiments it is not generic and is based on the assumption of alongshore uniformity that not necessarily holds along the Dutch coast or any other coast.

Including longshore effects in an empirical dune erosion model would require many more experiments and probably new research facilities. At complex dune coasts it seems therefore more appropriate to apply a generic dune erosion model that includes the longshore direction and predicts the morphodynamic evolution during a storm surge from the relevant physical processes.

Presently, the cross-shore processes involved in dune erosion are reasonably well understood. Several numerical models (SBeach (Larson et al., 1989), DUROSTA (Steetzel, 1993), CShore) can simulate the time dependent cross-shore evolution of a storm profile and associated dune erosion. However, none of these models can (or only partly) take into account longshore interactions as discussed in this paper. Recently a new model, XBeach, has been developed by Roelvink et al. (2009). This model for dune erosion, overwash and breaching fully includes the longshore direction and therefore seems a useful tool to asses complex dune systems in which longshore effects can be important for storm impact.

Storm impact on sandy dune coasts is usually considered a 1D cross-shore phenomenon. During a severe storm the water level rises and the beach is flooded. As a result storm waves can reach the dune and impact it, which causes episodical slumping of the dune face. The sediment that is released with a slump falls on the beach where it is picked up by relatively long waves that transport the sediment through the swash into the inner surf. Here a strong undertow is present and sediment suspensions (related to the intensity of (short) wave breaking) are high. Eroded dune sand remains in suspension in the inner surf and is transported even farther seaward until the strength of the undertow and the intensity of wave breaking decrease. Eventually, the sediment starts to settle and a new foreshore develops that is closer to equilibrium with the extreme hydraulic boundary conditions.

This cross-shore evolution of a coastal profile during a storm can be affected by longshore effects, which can locally reduce or amplify the impact of a storm on dunes. Longshore effects may evolve for several reasons as can be illustrated by some real world examples along the Dutch coast (see Figure 1).

A first example is the dune coast near the Hondsbossche and Pettemer sea defense (see upper left panel in Figure 1). The sea defense protrudes about 100 meters in front of the dune coast and at the transition from dike to dunes, longshore effects might be present. Since the availability of sand in front of the dunes is substantially larger with respect to the dike, the foreshore in front of the dunes is

\footnotetext{
${ }_{1}^{1}$ Deltares (formerly Delft Hydraulics), Delft, The Netherlands, PO Box 177, Delft, $2600 \mathrm{MH}$, The Netherlands

${ }_{3}^{2}$ Department of Civil Engineering and Geosciences, Delft University of Technology, Delft, The Netherlands

${ }^{3}$ Rosenstiel School of Marine and Atmospheric Science, University of Miami, Florida, USA
} 
expected to develop towards a higher elevation during a storm with respect to the foreshore in front of the dike. This will influence the wave height transformation towards the shore and associated longshore flow and sediment transport in case of obliquely incoming waves. Therefore at the transition from the dike towards the sandy dunes a gradient in the longshore sediment transport can be expected that (depending on the sign of the gradient) slows down or accelerates the cross-shore evolution of the foreshore in front of the dunes. In this example the situation just downstream of the dike is considered (see upper left panel in Figure 1) where the longshore transport gradient slows down the foreshore development. As a result near dune wave loads on the dunes are higher on average, which will cause a dune erosion hot spot due to longshore effects.
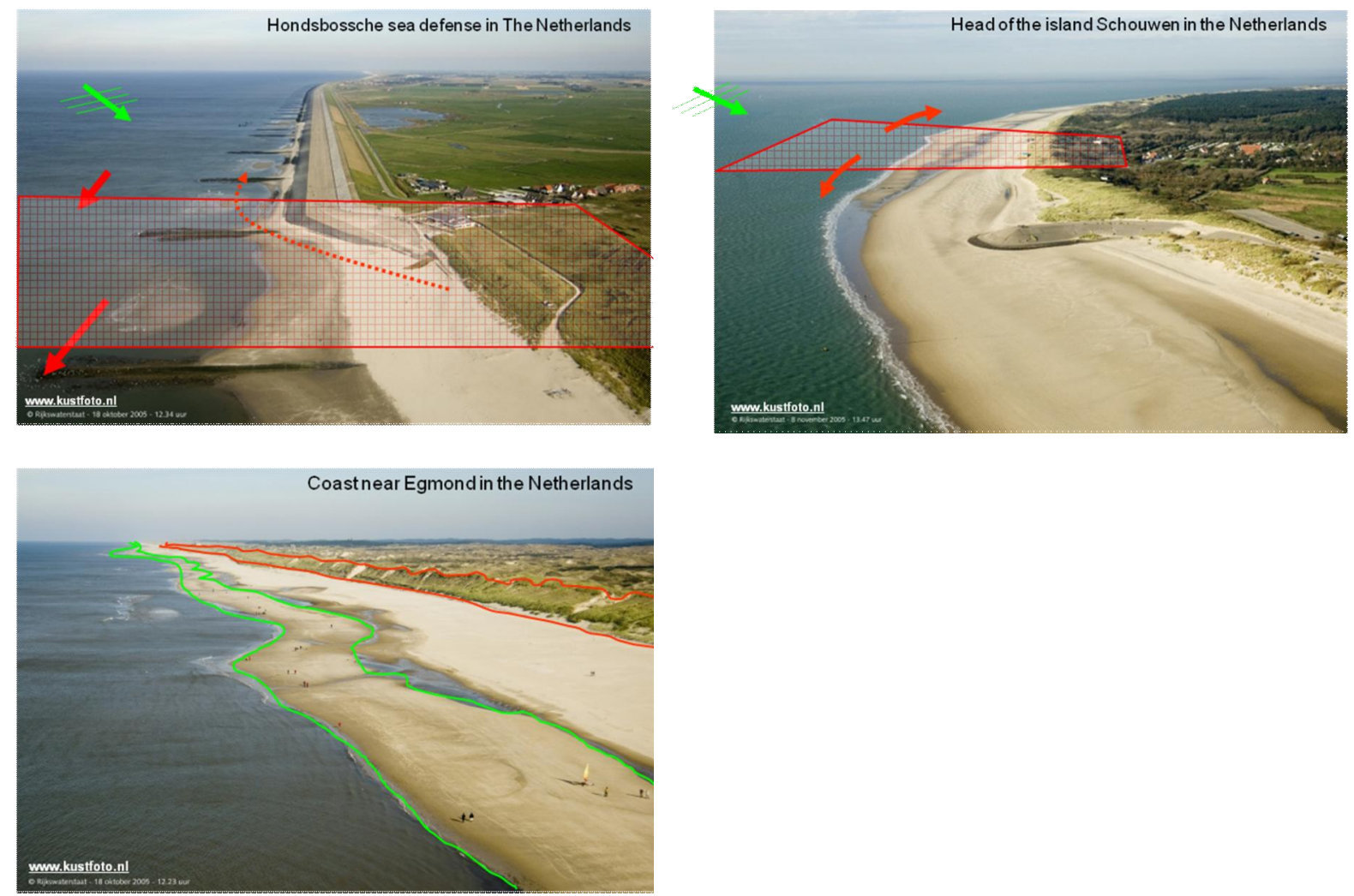

Figure 1: Situations along the Dutch coast where lonsghore effects can influence storm impact on the dunes.

A second example is the head of the island Schouwen (upper right panel in Figure 1). Here a strongly curved coastline is present and the orientation of each cross-shore transect in relation to the incoming waves is different. As a result there will be longshore sediment transport gradients, which can locally slow down or accelerate the cross-shore evolution of the foreshore during a storm causing erosion hot spots or cold spots respectively.

Finally, the coast just north of the town of Egmond Beach (lower left panel of Figure 1) looks reasonably uniform alongshore and at first sight it seems justified to assume that longshore interactions are negligible. However, a more detailed look reveals that the coast is not really uniform. The dune height varies in longshore direction and the dunes are intersected by notches and swirl holes, which affect the longshore availability of sand to build up a storm profile. Also, the bathymetry in front of the dunes contains several features including breaker bars intersected by rips, beach cusps and sand bars. These features will affect nearshore hydrodynamics and the forcing on the dunes.

In this paper the process-based area model XBeach is applied to explore possible longshore effects during storm surges that affect dune erosion and dune retreat. The situations considered are to some extend comparable to the coast a bit north of the city of Egmond. The starting point for the simulations is a uniform coast in which we introduce a couple of aspects that might introduce longshore effects. The following situations are discussed in presented simulations:

1. A longshore uniform dune coast to which a directionally spread wave field is imposed;

2. A dune coast with alongshore varying dune height and uniform bathymetry; 
3. A dune coast with alongshore varying bathymetry and constant dune topography

The paper starts with a model description and model setup for presented simulations (next section). Afterwards simulation results are presented and analyzed. The paper finishes with conclusions and discussion.

\section{MODEL AND SETUP}

Roelvink et al. (2009) developed a new process-based and time dependent 2DH model of the nearshore and coast called XBeach. This model solves coupled equations for cross shore and longshore hydrodynamics and morphodynamics on the time scale of wave groups, including the generation of infragravity waves. The model allows for variation in hydrodynamic forcing and morphological development in the longshore dimension. The hydrodynamics and morphodynamics of XBeach have been extensively calibrated and validated against (1D) flume experiments (Roelvink et al., 2008, 2009; van Thiel de Vries, 2009), and some (2DH) field cases (Roelvink et al., 2009, McCall et al., 2010).

\section{Model description}

XBeach solves the time-dependent short wave action balance on the scale of wave groups. The directional distribution of the short wave action density spectrum is taken into account in the model, whereas the frequency domain is represented by a single representative peak frequency, assuming a narrow banded incident spectrum (c.f. Goda, 1985). This approach is similar to the $2^{\text {nd }}$ generation spectral HISWA model (Holthuijsen et al., 1989), but includes time-dependency. Using these wave action formulations it is possible to solve directionally-spread infragravity waves and time-varying currents, as will be described below. The wave action balance is given as follows:

$$
\frac{\partial A}{\partial t}+\frac{\partial c_{g, x} A}{\partial x}+\frac{\partial c_{g, y} A}{\partial y}+\frac{\partial c_{\theta} A}{\partial \theta}=-\frac{D_{\text {breaking }}}{\sigma}
$$

Where $A=E / \sigma, E$ is the wave energy and $\sigma$ is the intrinsic wave frequency. The $\mathrm{x}$ - and $\mathrm{y}$ velocities $\left(c_{g, x}, c_{g, y}\right)$ in equation (1) represent the respective components of the wave group velocity. The velocity in directional space $\left(c_{\theta}\right)$ takes into account refraction due to bottom and currents. The energy dissipation due to wave breaking, $D_{\text {breaking }}$, is modeled according Roelvink (1993). XBeach includes a roller energy balance in order to redistribute energy from breaking waves to foam. Dissipation of short wave energy is used as a source term in the roller energy balance:

$$
\frac{\partial E_{\text {roller }}}{\partial t}+\frac{\partial c_{x} E_{\text {roller }}}{\partial x}+\frac{\partial c_{y} E_{\text {roller }}}{\partial y}+\frac{\partial c_{\theta} E_{\text {roller }}}{\partial \theta}=-D_{\text {roller }}+D_{\text {waves }}
$$

Roller energy dissipation is calculated according to Reniers (1997), following Deigaard (1993) and Svendsen (1984).

Surface elevation and flow, including infragravity waves and unsteady wave-induced currents, are solved using the shallow water momentum and mass balance equations. To include short waveinduced mass fluxes and return flows in shallow water, XBeach uses the Generalized Lagrangian Mean formulation (Andrews and McIntyre, 1978). The depth-average GLM-shallow water equations are given as follows:

$$
\begin{aligned}
& \frac{\partial u^{L}}{\partial t}+u^{L} \frac{\partial u^{L}}{\partial x}+v^{L} \frac{\partial u^{L}}{\partial y}-v_{h}\left(\frac{\partial^{2} u^{L}}{\partial x^{2}}+\frac{\partial^{2} u^{L}}{\partial y^{2}}\right)=-g \frac{\partial \eta}{\partial x}-\frac{c_{f} u^{E} \sqrt{\left(1.16 u_{r m s}\right)^{2}+\left(u^{E}\right)^{2}+\left(v^{E}\right)^{2}}}{h}+\frac{F_{x}}{\rho h} \\
& \frac{\partial v^{L}}{\partial t}+v^{L} \frac{\partial v^{L}}{\partial y}+u^{L} \frac{\partial v^{L}}{\partial x}-v_{h}\left(\frac{\partial^{2} v^{L}}{\partial y^{2}}+\frac{\partial^{2} v^{L}}{\partial x^{2}}\right)=-g \frac{\partial \eta}{\partial y}-\frac{c_{f} v^{E} \sqrt{\left(1.16 u_{r m s}\right)^{2}+\left(u^{E}\right)^{2}+\left(v^{E}\right)^{2}}}{h}+\frac{F_{y}}{\rho h}
\end{aligned}
$$




$$
\frac{\partial \eta}{\partial t}=-\frac{\partial u^{L} h}{\partial x}-\frac{\partial v^{L} h}{\partial y}
$$

L- and E-indexes for the $x(u)$ and $y(v)$ velocities refer to Lagrangian and Eulerian framework. Water depth is denoted by $h$, the water surface elevation by $\eta$ and the bed friction coefficient by $c_{f}$. The horizontal viscosity coefficient $\left(v_{h}\right)$ is modified by wave breaking in the surf zone, following Reniers et al. (2004). Bed friction is calculated using the parameterization of Feddersen et al. (2000). The wave and roller forcing terms $\left(F_{x}, F_{y}\right)$ in (3) and (4) are calculated from the short wave radiation stress gradients in $\mathrm{x}$ - and $\mathrm{y}$-direction, which are functions of the wave and roller energies.

Sediment transport rates are calculated as:

$$
\begin{aligned}
& S_{x}=h C u^{E}-D_{s} h \frac{\partial C}{\partial x} \\
& S_{y}=h C v^{E}-D_{s} h \frac{\partial C}{\partial y}
\end{aligned}
$$

in which $C$ is the depth-averaged sediment concentration and $D_{s}$ is the sediment diffusion coefficient. Sediment concentrations in the water column are modeled using a depth-averaged advection-diffusion scheme with a source-sink term based on an equilibrium sediment concentration (Galapatti and Vreugdenhil, 1985):

$$
\frac{\partial h C}{\partial t}+\frac{\partial h C u^{E}}{\partial x}+\frac{\partial h C v^{E}}{\partial y}+\frac{\partial}{\partial x}\left(D_{s} h \frac{\partial C}{\partial x}\right)+\frac{\partial}{\partial y}\left(D_{s} h \frac{\partial C}{\partial y}\right)=\frac{h C_{e q}-h C}{T_{s}}
$$

where $T_{s}$ is the sediment concentration adaptation time scale. The equilibrium concentration source-sink term $\left(C_{e q}\right)$ is calculated using a formulation of Van Rijn (2007) that is extended by including the effect of wave breaking induced turbulence:

$$
c_{e q}=\frac{A_{s b}}{h}\left(\sqrt{\left(u^{E}\right)^{2}+0.64 u_{r m s, 2}^{2}}-u_{c r}\right)^{1.5}+\frac{A_{s s}}{h}\left(\sqrt{\left(u^{E}\right)^{2}+0.64 u_{r m s, 2}^{2}}-u_{c r}\right)^{2.4}
$$

in which $A_{s s}$ and $A_{s b}$ are suspended and bed load transport coefficients respectively, $u_{c r}$ is the critical transport velocity due to currents and waves based on Shields and Komar and Miller (1975) respectively. The effect of wave breaking induced turbulence is included in the near-bed orbital velocity $u_{r m s, 2}$ following Reniers et al., (2004):

$$
u_{r m s, 2}=\sqrt{u_{r m s}^{2}+1.45 k_{b}}
$$

in which $k_{b}$ is the bore averaged near-bed turbulence energy (see Van Thiel de Vries, 2009 for more details).

Bed level change due to sediment transport rate gradients is assumed to occur on a time scale that is much longer than those associated with the hydrodynamic processes. Therefore, the time scale for the morphologic changes can be accelerated such that they take place at a rate that is still slower than the hydrodynamic processes, but occur rapidly enough to be relevant over a small number of hydrodynamic cycles. Thus:

$$
\frac{\partial z_{b}}{\partial t}=-\frac{f_{\text {mor }}}{(1-p)}\left(\frac{\partial S_{x}}{\partial x}+\frac{\partial S_{y}}{\partial y}\right)
$$

In which $f_{\text {mor }}$ is a morphological acceleration factor of $\mathrm{O}(1-10)$ and $p$ is the bed porosity. 
XBeach uses an avalanching algorithm in order to simulate dune slumping during storm conditions. Avalanching occurs if the bed slope exceeds a prescribed critical value for wet or dry points, as extensively tested by Van Thiel de Vries (2009).

\section{Area model setup}

The 2DH model covers an area of $4000 \mathrm{~m}$ alongshore and $3665 \mathrm{~m}$ cross-shore. The applied grid is uniform in longshore direction with $\mathrm{dy}=10 \mathrm{~m}$ and non-uniform in cross-shore direction with $\mathrm{dxmax}=25 \mathrm{~m}$ (at the offshore boundary) and dxmin $=5 \mathrm{~m}$ (in shallow water and the dune area). The bathymetry is based on a characteristic profile for the Dutch Holland coast (see e.g. Van Gent et al., 2008) to which, depending on the specific simulation, bathymetric or topographic features are added.

In all simulations the same storm is simulated, which is representative for the Dutch coast. The imposed hydrodynamic conditions vary during the simulation (Figure 2) using relations as proposed in Steetzel (1993). The duration of the storm surge considered is 45 hours from which only 32 hours are simulated (16 hours before and after the peak of the storm). At the start of the simulation the mean water level is about $0.9 \mathrm{~m}$ above mean sea level. The applied wave conditions are constructed from a JONSWAP spectrum with a directional spreading (Kuik et al., 1990) of about 12 degrees and the mean direction is shore normal.

At the lateral model boundaries walls are applied, meaning the lonsghore flow velocities are set to zero. To save computational time all simulations are performed with a morphological factor of ten.
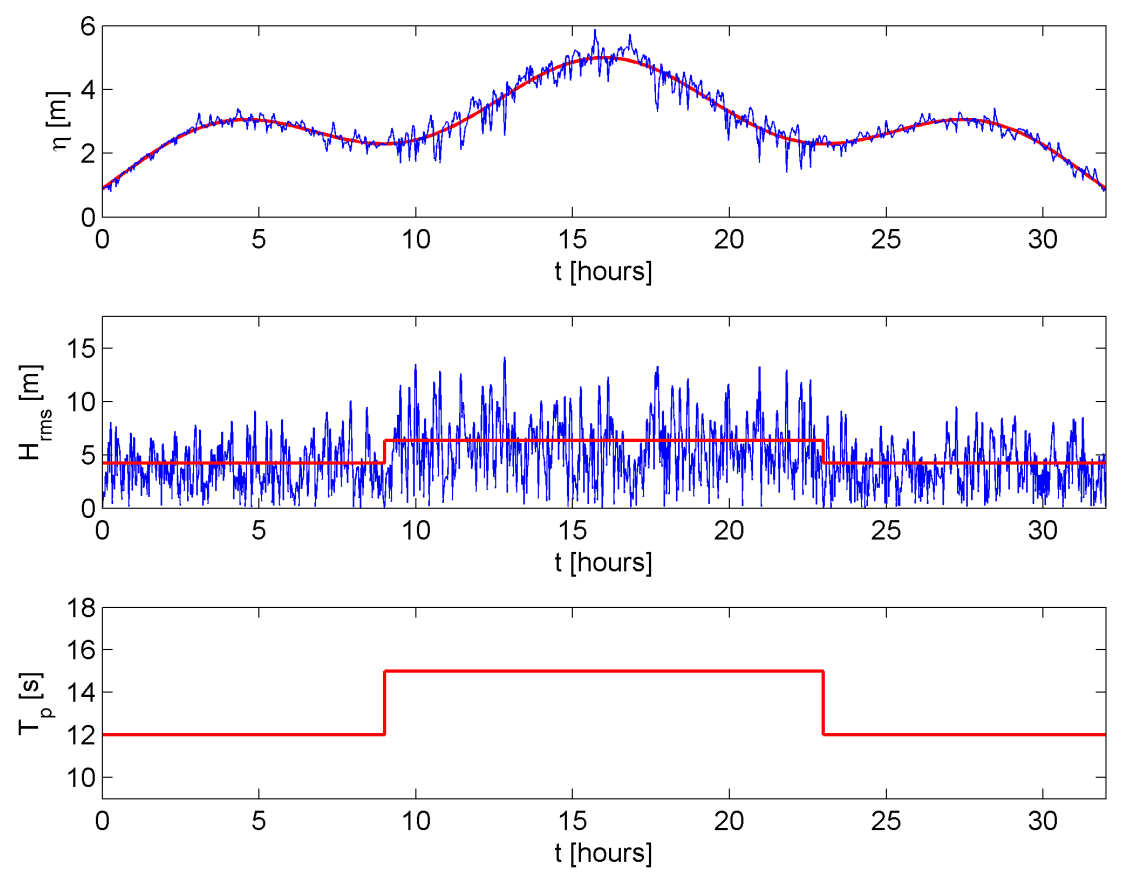

Figure 2: Imposed time varying hydrodynamic boundary conditions including storm surge (upper panel), wave height (middle panel) and peak wave period (lower panel). The red lines indicate the imposed boundary conditions and the blue lines represent XBeach output at the offshore model boundary. It is remarked that water surface elevations from the model include long wave variations and wave heights in the model vary on the wave group time scale.

\section{SIMULATION RESULTS}

\section{Longshore-uniform coast with directionally-spread forcing}

The understanding and modeling of dune erosion is mainly based on (large) scale flume experiments whereas field observations and experiments that include the longshore direction are rare. In the experiments usually a constant maximum storm surge level (Vellinga, 1986) is applied and waves are assumed to come in shore normal. In nature however the surge level varies during a storm and waves are directionally spread. As a result in nature dune erosion mechanisms and the associated retreat of the dune face might be different than found in a flume. For example near shore wave conditions are hypothesized to be less severe in case of directionally spread short waves. The short 
waves will refract, reducing the energy over a wave crest and the energy transfer from short waves to long waves is also expected to be less (Herbers et al. 1994, Reniers et al., 2002).

The aim of this section is to examine the effect of a directionally spread wave field on a longshore uniform sandy dune coast. To this end three simulations are conducted including a 1D simulation without directional spreading, a $2 \mathrm{DH}$ simulation without directional spreading and a $2 \mathrm{DH}$ simulation with a directionally spread wave field of 12 degrees. All simulations consider the same cross-shore profile, (cross-shore) computational grid and hydrodynamic boundary conditions (see area model setup for details).
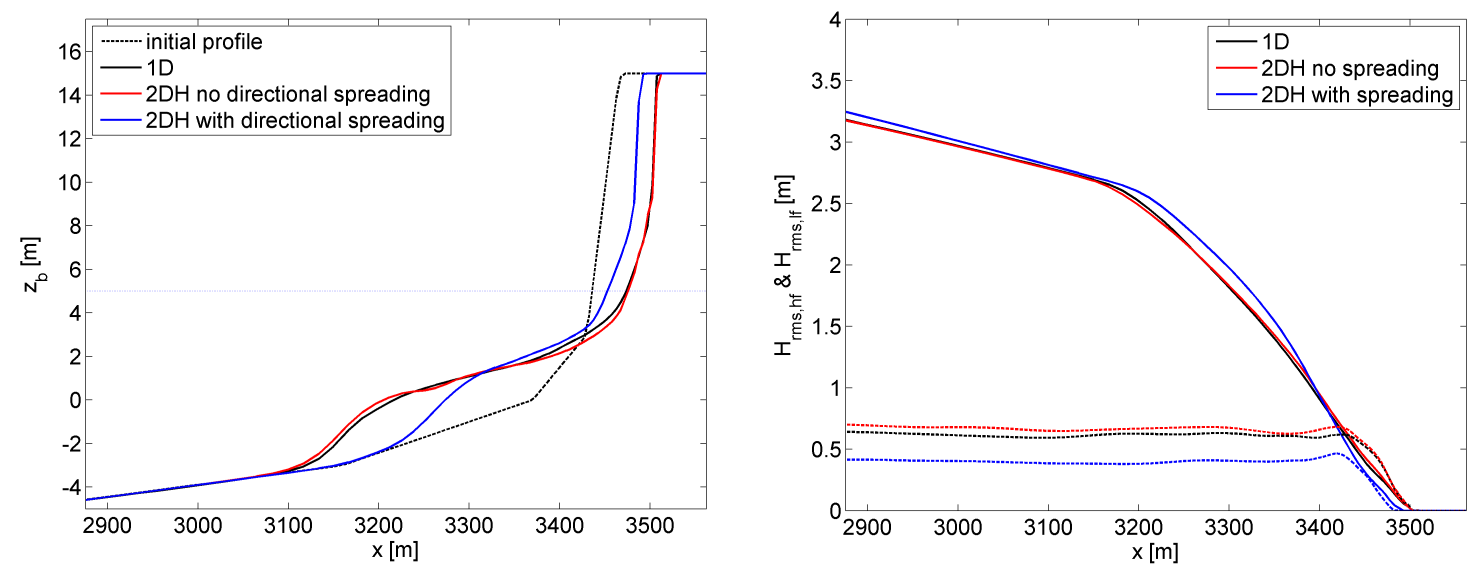

Figure 3: Left panel: longshore averaged pres-storm profiles (dotted lines) and post-storm profiles (solid lines). Right panel: longshore averaged transformations of short waves (solid lines) and long waves (dotted lines).
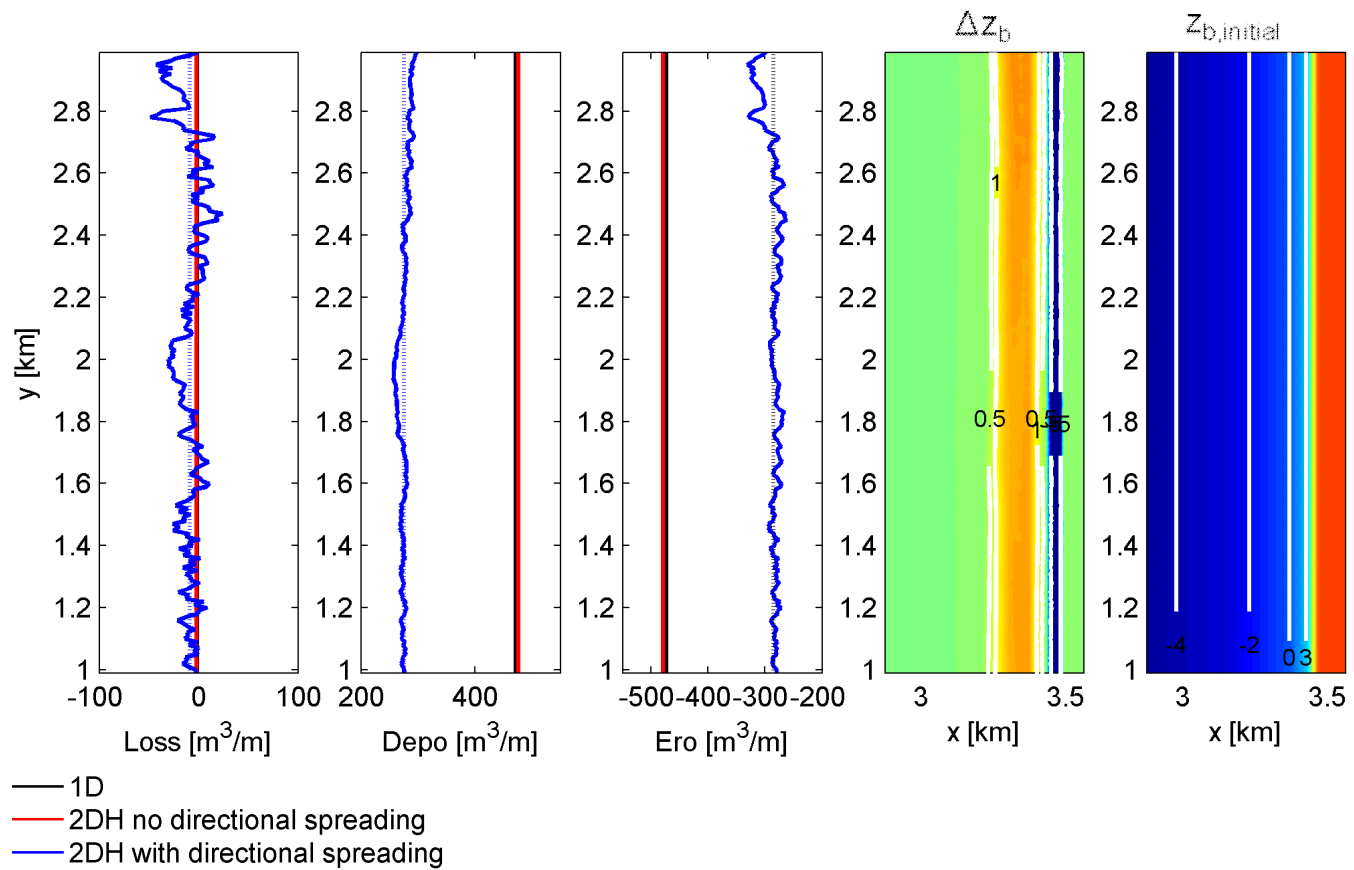

Figure 4: Simulations results as function of longshore distance including from left to right, the alongshore sediment loss, deposition volume below maximum storm surge level, dune erosion volume above maximum storm surge level, erosion deposition pattern and the initial bathymetry.

Longshore averaged simulation results are shown in Figure 3. The left panel indicates that profile evolution in simulations without directional spread waves are comparable for the 1D and 2DH simulation, which is expected for a robust implementation of the 2DH model. Including directionally spread waves, the storm impact on dunes is substantially less and dune erosion volumes above the maximum storm surge level decrease with order $40 \%$. A more detailed analysis reveals that in a 
directionally spread wave field the groupiness of the short waves reduces, resulting in about $50 \%$ less long wave variance in the nearshore area (compare dotted lines in the right panel of Figure 3 ). The long waves are generated by the interaction between short wave components. This interaction decreases as short wave components propagate at larger angles with eachother. In long-crested waves all short wave components propagate at the same angle of incidence and have maximum interaction to produce large bound long waves (see e.g. Herbers et al. 1994 and Reniers et al., 2002).

The nearshore short wave height transformation is found to be comparable in all simulations. Close to the dune face, short waves are higher in the simulation with directional spread waves, which can be explained by the different morphological evolution of the foreshore. Therefore, in the model, a decrease in dune erosion for a directionally spread wave field should be mainly explained by a reduction in the long wave variance. The strong coupling between long wave variance and dune erosion is in line with the model philosophy, which presumes that near dune hydrodynamics are dominated by wave group generated long waves.

An additional effect of including directional spread waves in a surf beat model is that, instantaneously, wave loads on the dunes can be non-uniform alongshore (directional spreading introduces wave groupiness in the longshore direction). As a result dune erosion rates can vary alongshore causing a slightly different development of the foreshore in time, which may provoke some longshore sediment exchange. This effect is indeed visible in the most left panel of Figure 4, which shows the sediment loss and gain from each cross-shore transect, which is a good estimate for longshore sediment exchange. In simulations without directional spreading the longshore sediment exchange is zero (as expected) whereas in the simulation with directional spreading some longshore interaction between cross-shore transects is observed. These longshore effects seem to be triggered by small variations in the longshore dune erosion volume (as can be seen in the middle panel of Figure 4). Looking at the longshore deposition of sediment (in the second panel from the left in Figure 4) these variations in erosion seem to be damped, which indicates a redistribution of sediment in the longshore direction. It is remarked that the sediment exchange in longshore direction is small and that the coast develops about uniform alongshore. Also it is expected that for simulations with a smaller morphological acceleration factor, the net longshore sediment exchange for a uniform coast will decrease (Near dune wave statistics will iterate towards the same distributions for a sufficiently large number of waves).

\section{Alongshore variation in dune topography}

Several observations show that after a storm surge the cross-shore position of the dune face hardly varies alongshore. In situations with longshore varying dune height this suggests that areas with higher dunes deliver also sand to build up a foreshore in areas with a smaller dune height (without any longshore effects it is expected that the dune with a smaller dune height experiences a larger setback in order to deliver the volume needed for a new equilibrium storm profile). Therefore, it is hypothesized that longshore varying processes should be present that transport eroded sand from higher dunes to the foreshore in areas with lower dunes.

The aim of this section is to examine the effect of alongshore variability in dune height on foreshore evolution during a storm surge. To this end three simulations are conducted including a 1D simulation for a low dune, a 1D simulation with a high dune and a 2DH simulation with directionally spread waves and a longshore varying dune height.

In the $2 \mathrm{DH}$ simulation, the applied bathymetry below the dune foot ( $3 \mathrm{~m}$ above mean water level) is based on the Dutch characteristic profile and is uniform alongshore. Above the dune foot elevation the topography locally deviates from the reference profile and is non-uniform alongshore. The dune crest elevation varies over a length of 500 meter between $15 \mathrm{~m}$ and $10 \mathrm{~m}$ above mean sea level. In all simulations the same (cross-shore) computational grid and hydrodynamic boundary conditions are applied (see model setup for more details).

Longshore averaged model results are shown in Figure 5. Looking at the 1D results first, it is seen that a coastal profile with a high dune develops differently to a coastal profile with a low dune. In the simulation with a low dune, the dune crests retreats much farther landward whereas the dune erosion volume above maximum storm surge is about 35\% larger in the simulation with a high dune. The latter can partly be explained by a shift in foreshore development in both simulations. In the simulation with a low dune, the dune crest retreats farther landward and as a result the developing 
foreshore is also shifted in that direction. Assuming the (equilibrium) shape of the foreshore is the same in both simulations, this landward shift of the foreshore reduces the sediment volume that is required to create the foreshore, resulting in smaller erosion volumes.

Longshore averaged simulation results for the $2 \mathrm{DH}$ simulation with directional spread waves and a longshore varying dune height (left panel Figure 5) reveal a much smaller storm impact on the dunes (both dune crest retreat and dune erosion volume are substantially less with respect to the 1D simulations). This smaller impact can again be explained by a reduction in the long wave variance (see right panel Figure 5) as a result of reduced groupiness in a directionally spread wave field.
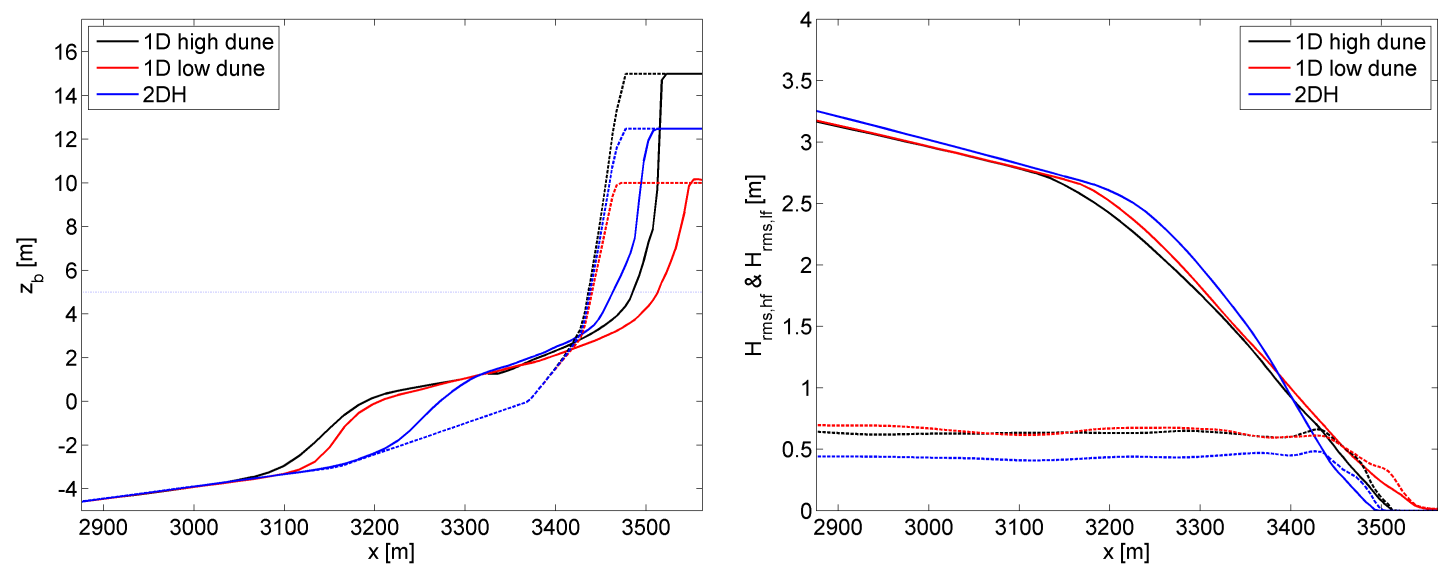

Figure 5: Left panel: longshore averaged pres-storm profiles (dotted lines) and post-storm profiles (solid lines). Right panel: longshore averaged transformations of short waves (solid lines) and long waves (dotted lines).
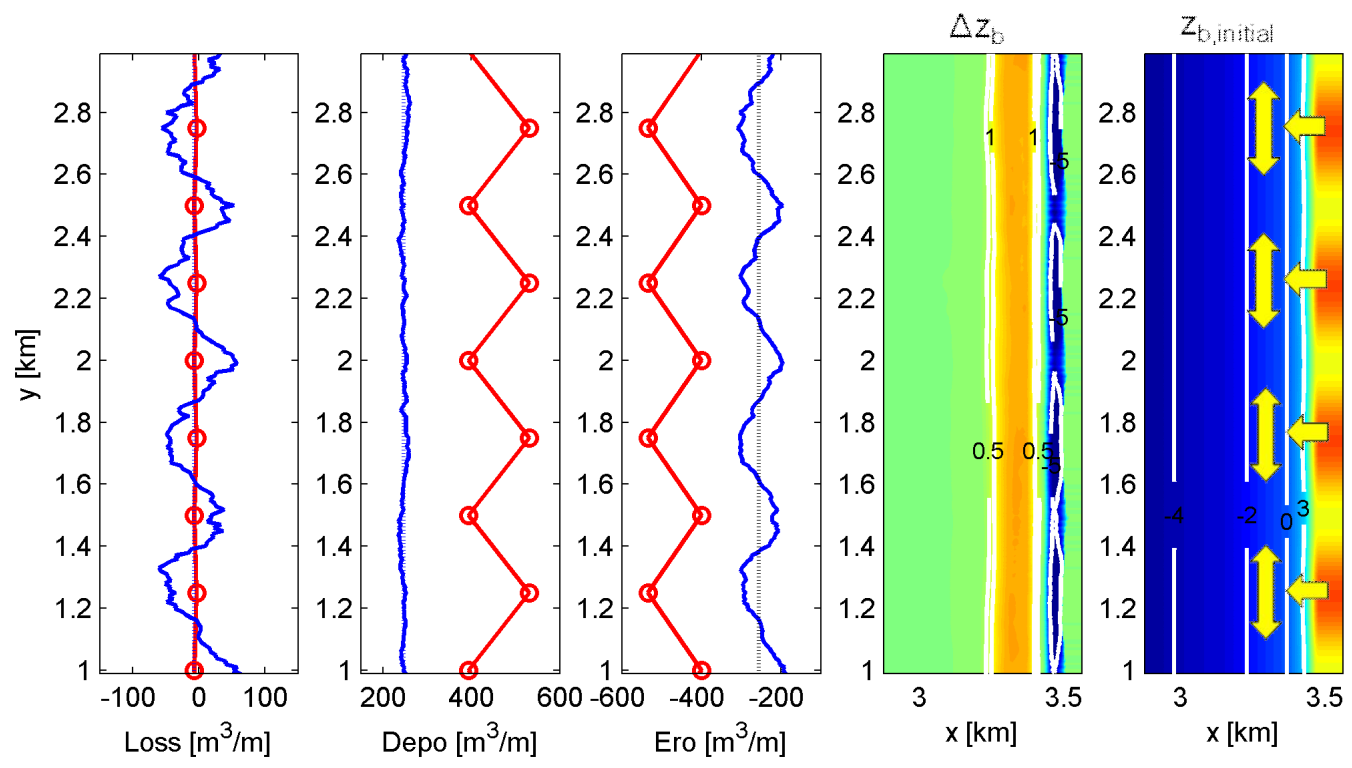

\section{D high dune \\ 1D low dune \\ $-2 \mathrm{DH}$}

Figure 6: Simulations results as function of longshore distance including from left to right, the alongshore sediment loss, deposition volume below maximum storm surge level, dune erosion volume above maximum storm surge level, erosion deposition pattern and the initial bathymetry.

A more detailed analysis of the 2DH simulation results can be made with Figure 6, which shows the simulated storm impact as function of the longshore direction. Looking at the simulated bed level changes (in the fourth panel of Figure 6) shows that the deposition depth on the fore shore is reasonably uniform alongshore whereas a strong variation in erosion height is visible. This variation correlates well with the dune height. In areas with high dunes the dune erosion volume (middle panel in Figure 6) is significant higher than at sections with low dunes whereas the deposition volume on 
the foreshore (second panel from left in Figure 6) is reasonably uniform alongshore. This means that there should be substantial sediment exchange in longshore direction as is indicated in the first panel from left in Figure 6. About $20 \%$ of the sand volume (this is about $50 \mathrm{~m}^{3} / \mathrm{m}$ ) that is eroded in sections with the highest dunes is used to build up the foreshore in sections with lower dunes. So in summary, the model predicts that low dunes are partly protected by the presence of high dunes whereas high dunes will experience stronger storm impact in the presence of lower dunes.

The simulated response in the $2 \mathrm{DH}$ model seems to be in line with visual observations in nature that reveal a uniform evolution of the foreshore and a uniform retreat of the dune face in longshore direction. It is remarked though that the strength of longshore sediment exchange is likely related to the length scale of dune height variation.

The longshore sediment exchange can be reconstructed with the time averaged flow field and sediment concentration field (Figure 7). The simulated sediment concentration field is reasonably uniform alongshore and the near dune flow field shows a time averaged longshore flow component such that sand from higher dunes is transported to areas with smaller dunes. The net result is that sediment from high dunes is (partly) transported towards the foreshore of low dunes.
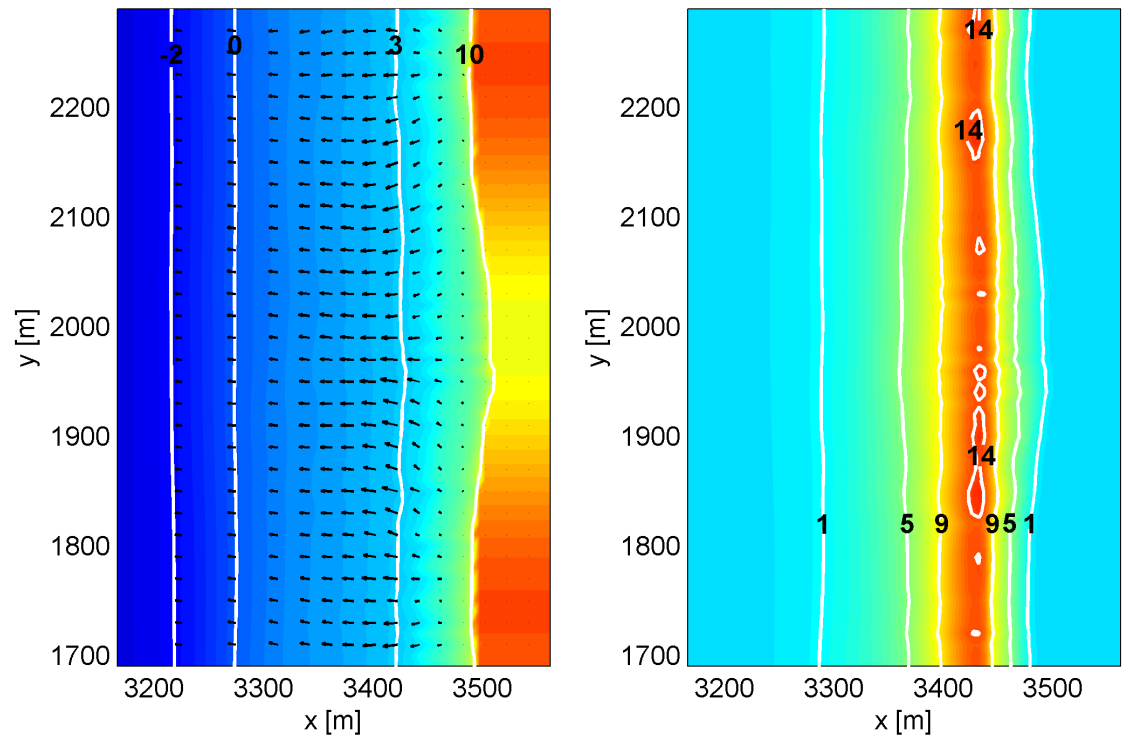

Figure 7: Left panel: detail of simulated time averaged flow field (vectors) over final bathymetry with depth contours in relation to mean sea levels. In front of high dunes the time averaged flow is offshore and directed towards the foreshore in front of the lower dunes. Right panel: detail of simulated time averaged sediment concentration field. Sediment concentrations are reasonably uniform alongshore.

\section{Alongshore variation in bathymetry}

At several locations along the Dutch coast the bathymetry contains alongshore non-uniform features as bars intersected by rips and beach cusps. Depending on the cross-shore location and magnitude, these features can affect near shore wave transformation and hydrodynamics during a storm surge. This could locally affect the dune erosion rate and may lead to a non-uniform retreat of the dune face. The aim of this section is therefore to examine the effect of an alongshore non-uniform bathymetry on dune erosion. To this end a $2 \mathrm{DH}$ simulation is conducted with shore normal directionally spread incoming waves. In addition to the 2DH simulation two 1D simulations are conducted for a cross-shore profile at the location of a rip and a cross-shore profile that contains breaker bars and a beach cusp (see Figure 8 for differences in initial profile).

The starting point for the bathymetry is the Dutch characteristic profile to which an offshore bar, an intertidal bar intersected by rips and beach cusps are added. The magnitude of the features is roughly in line with the situation at Egmond beach in The Netherlands. The amplitude of the outer breaker, inner breaker bars and beach cusp is $2 \mathrm{~m}, 2 \mathrm{~m}$ and $1.5 \mathrm{~m}$ respectively. The spacing between rips is 500 meters, which is equal to the length scale of dune height variation in the previous simulation. The cross-shore width of the features is $200 \mathrm{~m}$. In all simulations the same (cross-shore) computational grid and hydrodynamic boundary conditions (see previous section for details) are applied. 
As in the previous simulations first the longshore averaged simulation results are analyzed (see Figure 8). Starting with the 1D simulations it is seen that predicted storm impact is different for a rip transect than for a transect containing bar and cusp type features (left panel Figure 8). In the rip profile simulation, the dune face retreats farther landward and simulated dune erosion volume is $\mathrm{xx} \%$ higher. The difference in storm impact for the rip profile and bar profile can be explained from the differences in pre-storm profiles. Initially, the foreshore of the rip profile contains substantially less sediment with respect to bar profile. As a result the rip profile needs more sediment from the dunes to build up the same (storm equilibrium) foreshore. The effect of the initial profile is also visable in the wave height transformation towards the dune (right panel Figure 8), which shows that the incoming short wave height is dissipated farther seaward in the bar profile resulting in on average a smaller near dune wave height.

Longshore averaged simulation results for the $2 \mathrm{DH}$ simulation with directional spread waves and a longshore varying bathymetry (left panel Figure 8) reveal a much smaller storm impact on the dunes (both dune crest retreat and dune erosion volume are substantially less with respect to the 1D simulations). This smaller impact is consistent with previous results and can again be explained by a reduction in the long wave variance (see right panel Figure 8) as a result of reduced groupiness in a directionally spread wave field.

A more detailed analysis of the 2DH simulation results can be made with Figure 9, which shows the simulated storm impact as function of the longshore direction. Looking at the simulated bed level changes (in the fourth panel from left in Figure 9) shows that the deposition depth on the foreshore varies strongly alongshore and is much higher in the rip channels. Also dune face retreat and dune erosion volumes (middle panel Figure 9) vary alongshore and are highest in the rip transects, which is consistent with the 1D simulations.

Comparing erosion volumes and deposition volumes alongshore (second and third panel from left in Figure 9) reveals that the alongshore variation in the foreshore deposition volume is even higher with respect to the longshore variation in dune erosion. This can be explained by longshore sediment exchange as is illustrated in the first panel from left in Figure 9. The 2DH simulation results suggest that bar transects deliver extra sediment to rip transects (maximum of about $50 \mathrm{~m}^{3} / \mathrm{m}$, which is about $20 \%$ of the dune erosion volume).

In the model there is a correlation between the dune erosion volume and the location of rip currents. However, this correlation evolves mainly from cross-shore processes and longshore interactions are more likely to damp the coupling between rips and dune erosion volume since interactions alongshore partly fulfill the extra sediment demand in the rips. It is expected that the longshore spacing between rips (500 meter in this simulation) will influence the longshore sediment exchange and will increase for a smaller spacing.
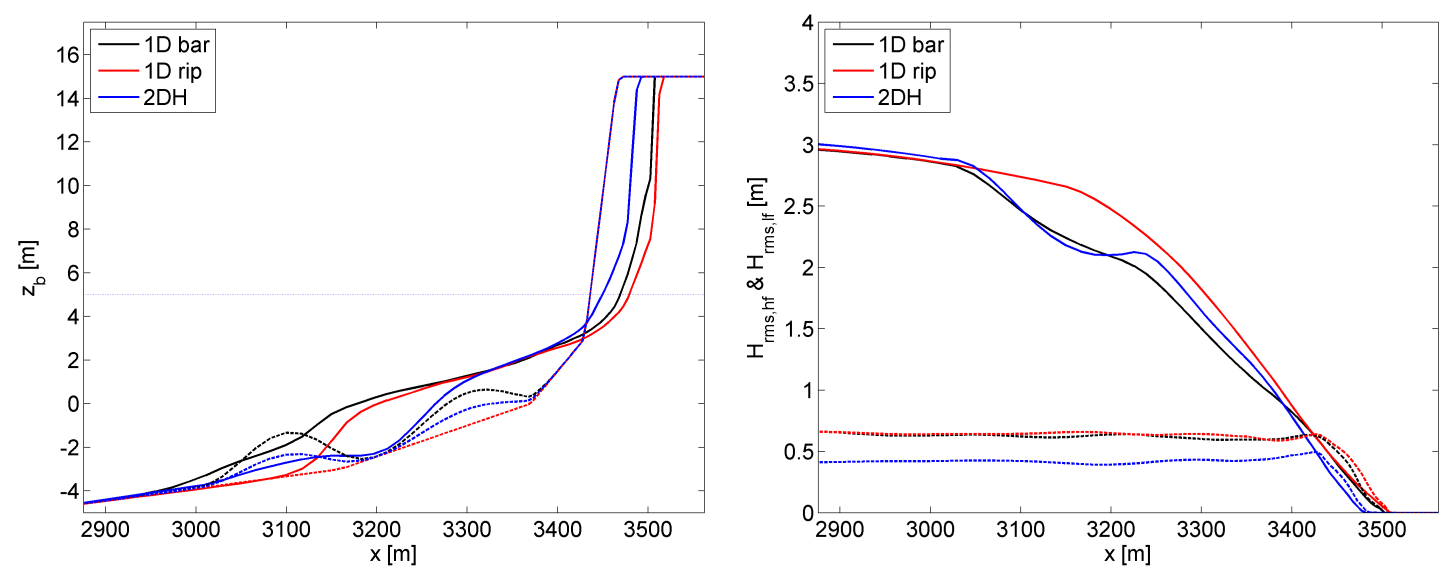

Figure 8: Left panel: longshore averaged pres-storm profiles (dotted lines) and post-storm profiles (solid lines). Right panel: longshore averaged transformations of short waves (solid lines) and long waves (dotted lines). 

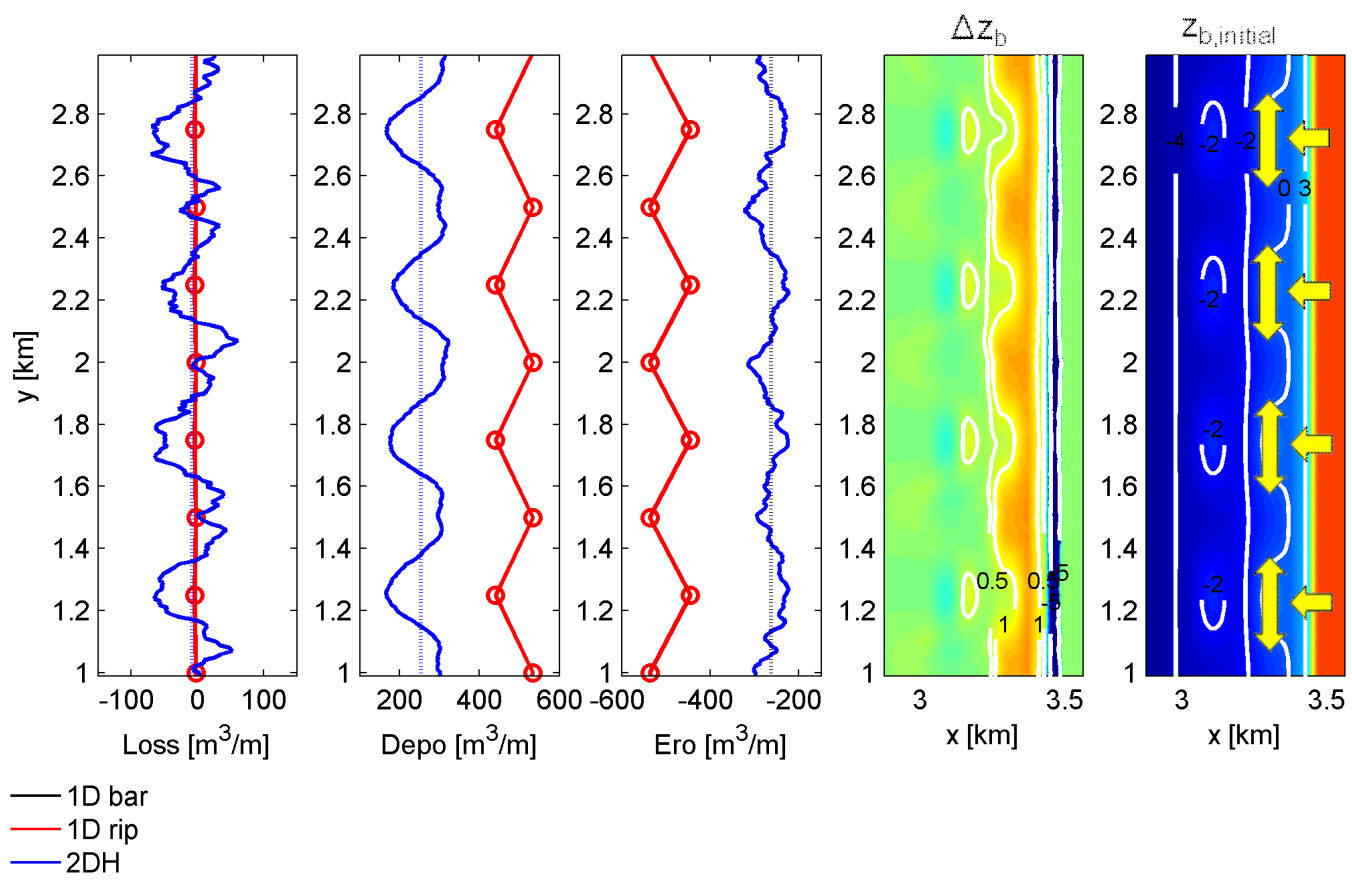

Figure 9: Simulations results as function of longshore distance including from left to right, the alongshore sediment loss, deposition volume below maximum storm surge level, dune erosion volume above maximum storm surge level, erosion deposition pattern and the initial bathymetry.

The longshore sediment exchange can be further explained with the time averaged flow field and sediment concentration field (Figure 10). The simulated flow field shows a time averaged longshore flow component such that transects with more sand containing breaker bars and beach cusps deliver sand to the foreshore at rip locations. The simulated time averaged sediment concentration field also varies alongshore and is higher in front of the rip locations indicating that offshore transport capacity in front of the dunes is larger here.
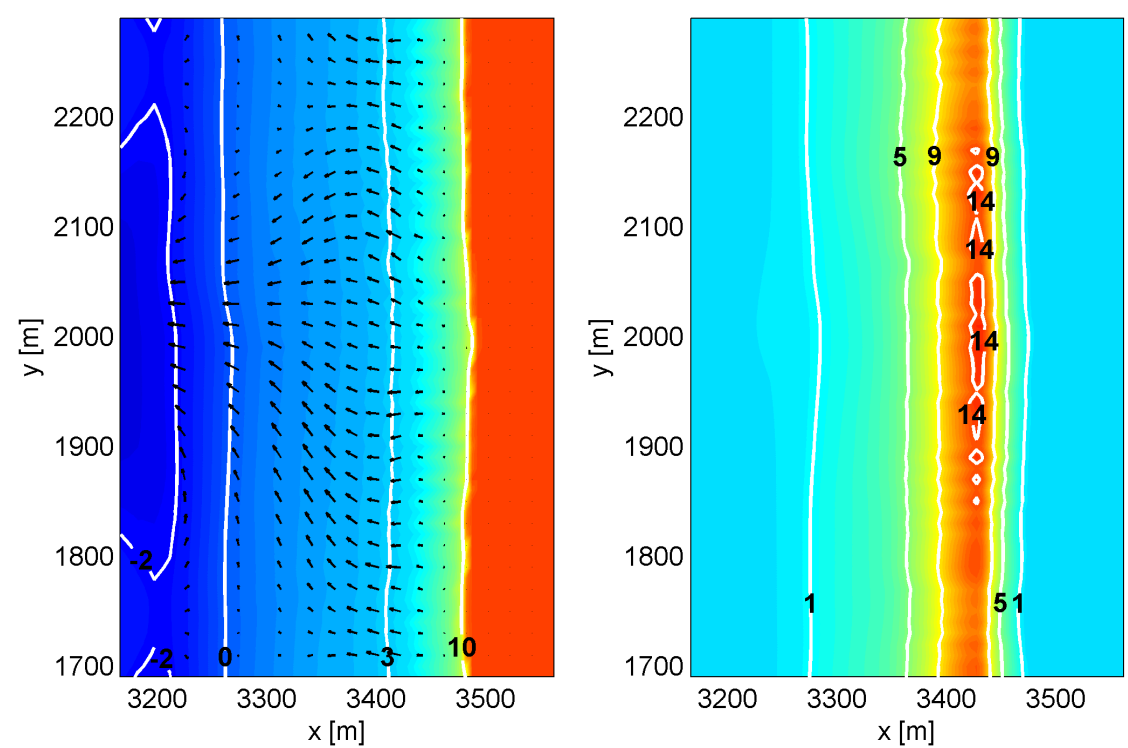

Figure 10: Left panel: detail of simulated time averaged flow field (vectors) over final bathymetry with depth contours in relation to mean sea levels. In transects with breaker bars and beach cusps the time averaged flow is offshore and directed towards the foreshore that contains a rip (at $\mathrm{y}=2000 \mathrm{~m}$ ). Right panel: detail of simulated time averaged sediment concentration field. Sediment concentrations are reasonably uniform alongshore 


\section{CONCLUSIONS AND DISCUSSION}

Exploratory simulations to examine the effect of the longshore dimension on dune erosion with an area model reveal that:

1. Including directional spread waves (of 12 degrees), the groupiness of the incoming short waves is reduced, which results in order $50 \%$ less long wave variance. This $50 \%$ reduction in long wave variance results in order $40 \%$ less dune erosion above storm surge level.

2. Longshore variation in bathymetry and topography introduce longshore effects that damp longshore variations in profile evolution. Due to this effect, storm impact on dunes can locally be higher. A simulation with alongshore varying dune height shows that areas with high dunes experience more erosion in the presence of low dunes since sand from these higher dunes is partly used to develop a storm profile in low dune areas. A simulation with a bar system intersected by rips indicates that rip locations are positively correlated to dune erosion hot spots. However this correlation can be explained from cross-shore processes and longshore effects in the model seem to reduce the strength of the correlation between rip location and erosion hot spot.

The presented simulation results suggest that longshore effects on dune erosion can be substantial, also in situations that look reasonably uniform at first sight (e.g the town of Egmond Beach in The Netherlands). This asks for a detailed verification of the model results with measurements from field and laboratory. However, dune erosion experiments that include longshore measurements are scarce, especially for the extreme conditions studied here.

Including the effect of directional spread waves in the model suppresses the long wave variance, which results in a huge reduction of storm impact on dunes. The reduction in long wave variance as a result of directional spreading can also be explained theoretically (see e.g. Herbers et al. 1994 and Reniers et al., 2002). The morphological model sensitivity to directional spreading can less easy be verified. In the presented model it is hypothesized that near dune hydrodynamics and the interaction of swash and dune face are mostly related to long waves. This assumption was found to be true at dissipative beaches in (approximately) 1D cases (Van Thiel de Vries et al., 2006). The interaction between long wave swash and dune is solved with an elegant avalanching algorithm, but can benefit from further validation and a better physical interpretation.

Longshore effects for the simulations with varying dune topography and varying bathymetry can be explained in more detail by longshore variations in the time averaged flow field and sediment concentration field. In the near dune area turbulence intensities are high, which tends to damp longshore gradients in both flow and sediment suspensions. In presented simulations the apparent viscosity and sediment diffusivity due to wave breaking induced turbulence is high, but not sufficiently high to damp substantial longshore effects.

\section{ACKNOWLEDGMENTS}

The Dr.Ir. Cornelis Lely Foundation and the Delft Cluster II joint research program are gratefully acknowledged for the financial support to this work.

In addition the research leading to presented results has received funding from the European Community's Seventh Framework Programme under grant agreement n ${ }^{\circ} 202798$ (MICORE Project), from funding by the Netherlands Dept. of Public Works (Waterdienst), under the SBW (Strengths and Loads of Sea Defences) project 1200116 (AvD, JvTdV and PvG), and Deltares Strategic Research funding (Projectnumber 1200266).

\section{REFERENCES}

Andrews, D.G., McIntyre, M.E., 1978. An exact theory of nonlinear waves on a Lagrangian-mean flow. Journal of Fluid Mechanics 89 (4), 609-646.

Deigaard, R., 1993. A note on the three dimensional shear stress distribution in a surf zone. Coastal Engineering, 20(1-2): 157-171. 
Feddersen, F., Guza, R.T., Elgar, S., Herbers, T.H.C., 2000. Velocity moments in alongshore bottom stress parameterizations. Journal of Geophysical Research 105 (C4), 8673-8686.

Galapatti, R., Vreugdenhil, C.B., 1985. A depth-integrated model for suspended sediment transport. Journal of Hydraulic Research 23 (4), 359-377.

Goda, Y., 1985. Random Seas and Design of Maritime Structures. University of Tokyo Press, Tokyo.

Herbers, T. H. C., S. Elgar, and R. T. Guza (1994), Infragravity-frequency (0.005-0.05 Hz) motions on the shelf: I. Forced waves, J. Phys. Oceanogr, 24, 917- 927.

Holthuijsen, L.H., Booij, N. and Herbers, T.H.C., 1989. A prediction model for sta-tionary short crested waves in shallow water with ambient currents. Coastal Engineering, 13(1): 23-54.

Komar, P.D. and Miller, M.C., 1975. On the comparison between the threshold of sediment motion under waves and unidirectional currents with a discussion of the pratical evaluation of the threshold. Journal of Sedimentary Petrology, 45: 362-367.

Larson, M., Kraus, N.C. and Byrnes, M.R., 1989. SBeach: Numerical model for simu-lating storminduced beach change. Report 1: Empirical foundation and model development, U.S. Army Engineer Waterways Experiment Station, Coastal Engineering Research Center, Vicksburg, MS.

McCall, R.T., J.S.M. Van Thiel de Vries, N.G. Plant, A.R. Van Dongeren, J.A. Roelvink, D.M. Thompson, A.J.H.M. Reniers (2009). Two-dimensional time dependent hurricane overwash and erosion modelling at Santa Rosa Island. Coastal Engineering, Vol. 57, 7, pp. 668-683, DOI: 10.1016/j.coastaleng.2010.02.006.

Reniers, A.J.H.M. and Battjes, J.A., 1997. A laboratory study of longshore currents over barred and nonbarred beaches. Coastal Engineering, 30(1-2): 1-21.

Reniers, A.J.H.M., Van Dongeren, A.R., Battjes, J.A. and Thornton, E.B., 2002. Linear modelling of infragravity waves during Delilah. Journal of Geophysical Research, 107(C10): doi:10.1029/2001JC001083.

Reniers, A.J.H.M., Roelvink, J.A. and Thornton, E., 2004. Morphodynamic modeling of an embayed beach under wave group forcing. Journal of Geophysical Re-search, 109(C01030): doi: 10.1029/2002JC001586.

Roelvink, J.A., 1993. Surf beat and its effect on cross-shore profiles. PhD Thesis, Delft University of Technology, Delft, The Netherlands.

Roelvink. J.A., A.J.H.M. Reniers, A.R. Van Dongeren, J.S.M. Van Thiel de Vries, R. McCall, J. Lescinski, in press, Modeling strom impacts on beaches, dunes and barrier islands. Coastal Engineering, doi:10.1016/j.coastaleng. 2009.08.006

Steetzel, H.J., 1993. Cross-shore transport during storm surges. PhD Thesis, Delft University of Technology, Delft, The Netherlands.

Svendsen, I.A., 1984. Wave heights and set-up in a surf zone. Coastal Engineering, 8(4): 303-329.

Van Gent, M.R.A., Van Thiel de Vries, J.S.M., Coeveld, E.M., De Vroeg, J.H. and Van de Graaff, J., 2008. Large-scale dune erosion tests to study the influence of wave periods. Coastal Engineering, 55(12): 1041-1051.

Van Rijn, L.C., 2007. Unified view of sediment transport by currents and waves, part I, II, III and IV. Journal of Hydraulic Engineering, 133(6,7): 649-689 (part I \& II), 761-793 (part III \& IV).

Van Thiel de Vries, J.S.M., Van de Graaff, J., Raubenheimer, B., Reniers, A.J.H.M. and Stive, M.J.F., 2006. Modeling inner surf hydrodynamics during storm surges, 30th International Conference on Coastal Engineering, San Diego, USA, pp. 896-908.

Van Thiel de Vries, J.S.M., 2009, Dune erosion during storm surges, PhD Thesis, Delft University of Technology, Delft, The Netherlands, 202 pp.

Vellinga, P., 1986. Beach and dune erosion during storm surges. PhD Thesis, Delft University of Technology, Delft, The Netherlands, 169 pp. 